\title{
Toward Greater Scrutiny of Dialysate Flow: Reply to the Letter to the Editor of Dr. Molano-Triviño and Colleagues
}

\author{
Luis Alvarez $^{\mathrm{a}}$ John K. Leypoldt ${ }^{\mathrm{b}}$ Sarah Prichard ${ }^{\mathrm{c}}$ Glenn M. Chertow ${ }^{\mathrm{d}}$ \\ a Palo Alto Medical Foundation, Palo Alto, CA, USA; ${ }^{\mathrm{b}}$ San Clemente, CA, USA; ${ }^{\mathrm{C}}$ Montreal, QC, Canada; ${ }^{\mathrm{d}}$ Stanford \\ University School of Medicine, Stanford, CA, USA
}

Dear Editor,

We are pleased to respond to the letter of Dr. Molano-Triviño and colleagues regarding our article on Differential Molecular Modeling Predictions of Mid and Conventional Dialysate Flows [1].

Dr. Molano-Triviño and colleagues report their interest on dialysate waste water reduction, and on dialysis efficiency and safety.

We agree that water conservation in dialysis is a critically important topic. It is estimated that one-third of the world's ground-water systems are already in distress [2], and that half the global population is already living in water-scarce geographies [3]. Dr. John Agar has previously reported on the monumental environmental impact (vis-à-vis water and carbon footprint) of dialysis therapies [4], and these initial observations have been expanded upon by Dr. Molano-Triviño and colleagues in their Blue Planet dialysis report [5]. Our report predicts that a majority of patients could receive adequate small solute clearance at a dialysate flow of $300 \mathrm{~mL} /$ min, extending Dr. Molano-Triviño's observations on water saving from $120 \mathrm{~L}$ per 4 -h session down to $72 \mathrm{~L}$ or a $40 \%$ improvement in water utilization relative to commonly applied dialysate flow rates. We believe that these water conservation estimates are conservative, since newer dialysis technologies produce less "gray water" with highly efficient reverse osmosis permeate production and permeate production occurring only during treatment. In addition, the carbon footprint of hemodialysis can be further reduced with less electrical demand and need for less intensive infrastructure development: for example, waste water drainage occurring with standard 1-inch drains, rather than 3-inch drainage with associated declination needs that are typically required by high dialysate production facilities.

Regarding safety and dialysis efficiency, we are gratified to learn about the results of Dr. Molano-Triviño and colleagues' realworld experience on dialysate reduction showing no significant effects on urea clearance on the population studied. Our results would predict that those observations could be extended to patients weighing $70 \mathrm{~kg}$ or more. We would remind our colleagues that we do not show "no differences" in predicted urea clearance but rather differences that are very small, and in larger patients, a minimum $\mathrm{Kt} / \mathrm{V}_{\text {urea }}$ of 1.2 can be achieved using a dialysate flow rate of $300 \mathrm{~mL} / \mathrm{min}$ with no $>15 \mathrm{~min}$ of additional treatment time. Moreover, as Molano-Triviño and colleagues suggest, there may be no clinically significant differences in outcomes in vivo.

Finally, we agree that much greater scrutiny should be applied to current assumptions regarding higher dialysate flows being clinically better in all clinical situations.

\section{Disclosure Statement}

Drs. Luis Alvarez, John K. Leypoldt, Sarah Prichard, and Glenn M. Chertow are advisors to Outset Medical.
Luis Alvarez, $\mathrm{MD}, \mathrm{PhD}$ 


\section{References}

1 Leypoldt JK, Prichard S, Chertow GM, Alvarez L. Differential molecular modeling predictions of mid and conventional dialysate flows. Blood Purif. 2019;47(4):36976.

2 Richey AS, Thomas BF, Lo MH, Reager JT, Famiglietti JS, Voss K, et al. Quantifying renewable groundwater stress with GRACE. Water Resour Res. 2015 Jul;51(7):5217-38.
3 Burke P, Satoh Y, Fischer G, Kahil MT, Scherzer A, Tramberend S, et al. Water Futures and Solution Fast Track Initiative Final Report. Laxenburg, Austria: International Institute for Applied Systems Analysis; 2016.
4 Agar JM. Personal viewpoint: HemodialysisWater, power and waste disposal: Rethinking our environmental responsibilities. Hemodialysis Int. 2011;16:6-10.

5 Molano-Triviño A, Wancjer B, Neri MM Karopadi AN, Rosner M, Ronco C. Blue Planet dialysis: novel water-sparing strategies for reducing dialysate flow. Int J Artif Organs. 2017 Nov;41:3-10 